\title{
Developing one-dimensional implosions for inertial confinement fusion science
}

J. L. Kline ${ }^{1}$, S. A. $\mathrm{Yi}^{1}$, A. N. Simakov ${ }^{1}$, R. E. $\mathrm{Olson}^{1}$, D. C. Wilson ${ }^{1}$, G. A. Kyrala ${ }^{1}$, T. S. Perry ${ }^{1}$, S. H. Batha ${ }^{1}$, E. L. Dewald ${ }^{2}$, J. E. Ralph ${ }^{2}$, D. J. Strozzi², A. G. MacPhee ${ }^{2}$, D. A. Callahan ${ }^{2}$, D. Hinkel ${ }^{2}$, O. A. Hurricane ${ }^{2}$, R. J. Leeper ${ }^{1}$, A. B. Zylstra ${ }^{1}$, R. R. Peterson ${ }^{1}$, B. M. Haines ${ }^{1}$, L. Yin ${ }^{1}$, P. A. Bradley ${ }^{1}$, R. C. Shah ${ }^{1}$, T. Braun ${ }^{2}$, J. Biener ${ }^{2}$, B. J. Kozioziemski², J. D. Sater ${ }^{2}$, M. M. Biener ${ }^{2}$, A. V. Hamza ${ }^{2}$, A. $\mathrm{Nikroo}^{2}$, L. F. Berzak Hopkins ${ }^{2}$, D. $\mathrm{Ho}^{2}$, S. LePape ${ }^{2}$, N. B. Meezan ${ }^{2}$, D. S. Montgomery ${ }^{1}$, W. S. Daughton ${ }^{1}$, E. C. Merritt ${ }^{1}$, T. Cardenas ${ }^{1}$, and E. S. Dodd ${ }^{1}$

${ }^{1}$ Los Alamos National Laboratory, Los Alamos, NM, USA

${ }^{2}$ Lawrence Livermore National Laboratory, Livermore, CA, USA

(Received 3 May 2016; revised 29 September 2016; accepted 25 October 2016)

\begin{abstract}
Experiments on the National Ignition Facility show that multi-dimensional effects currently dominate the implosion performance. Low mode implosion symmetry and hydrodynamic instabilities seeded by capsule mounting features appear to be two key limiting factors for implosion performance. One reason these factors have a large impact on the performance of inertial confinement fusion implosions is the high convergence required to achieve high fusion gains. To tackle these problems, a predictable implosion platform is needed meaning experiments must trade-off high gain for performance. LANL has adopted three main approaches to develop a one-dimensional (1D) implosion platform where 1D means measured yield over the 1D clean calculation. A high adiabat, low convergence platform is being developed using beryllium capsules enabling larger case-to-capsule ratios to improve symmetry. The second approach is liquid fuel layers using wetted foam targets. With liquid fuel layers, the implosion convergence can be controlled via the initial vapor pressure set by the target fielding temperature. The last method is double shell targets. For double shells, the smaller inner shell houses the DT fuel and the convergence of this cavity is relatively small compared to hot spot ignition. However, double shell targets have a different set of trade-off versus advantages. Details for each of these approaches are described.
\end{abstract}

Keywords: beryllium capsules; double shells; inertial confinement fusion; liquid layers

\section{Introduction}

While progress towards laser-based indirect drive inertial confinement fusion (ICF) is being made ${ }^{[1-3]}$, experimental results show challenges remain. Recent modeling of implosion experiments for both low and high adiabat implosions has identified specific issues that are believed to impact the performance for each type of implosion ${ }^{[4]}$. For the high convergence, low adiabat implosions, the dominant mechanisms believed to degrade performance are hydrodynamic instabilities seeded by capsule mounting hardware such as the fill tube, tenting ${ }^{[5,6]}$ used to hold the capsule in place and capsule surface roughness, as well as low mode asymmetries. High adiabat implosions, designed to reduce

Correspondence to: J. L. Kline, MS E526, PO Box 1663, Los Alamos, NM 87545, USA. Email: jkline@lanl.gov the effect of ablation front hydrodynamic instabilities, as well as a reduced convergence, are impacted primarily by low mode implosion shape. In both cases, shape and hydrodynamic instability play a key role. While there may be other degradation mechanisms, they are difficult to assess without addressing the afore-mentioned issues. Thus, the near term goal for ICF experiments on the NIF is to mitigate these known effects by pushing towards round implosions while addressing high mode perturbations to maximize onedimensional (1D) implosion behavior, i.e., high yield over 1D clean (no mix) simulations. The most straight forward means to do this is to retreat from aggressive ICF designs by reducing the implosion convergence, defined as the initial outer radius to the final hot spot $\mathrm{x}$-ray self-emission radius, and increasing the case-to-capsule ratio, defined as the hohlraum to capsule outer radius. This should provide a more predictable platform that can be used to study 
ignition physics, test mitigation strategies for uncovered issues, benchmark simulations models, and ultimately to evaluate what is needed to achieve ignition.

Los Alamos National Laboratory (LANL) has adopted the strategy of increasing the case-to-capsule ratio and reducing the convergence ratio for each of its ignition campaigns as a means to achieve 1D like behavior. There are currently three major ICF campaigns under way at LANL. The first is a large case-to-capsule, low radiation temperature target design that takes advantage of beryllium capsules ${ }^{[7-10]}$. The second approach uses Deuterium-Tritium (DT) liquid layered targets in which the convergence ratio is controlled by varying the initial mass in the central cavity of the capsule through the vapor pressure. The last approach uses double shell targets that are comprised of an inner shell filled with the DT fuel surrounded by an outer shell with a foam fill between the shells. The inner shell filled with the fusion fuel is expected to have a convergence of $\sim 10$, consistent with the premise of reduced convergence assuming the inner shell convergence dominates not that of the whole capsule. The outer shell of the double shell targets attempts to mitigate issues with driver/target coupling. In this manuscript, a description of each approach will be given including the key strategic benefits.

\section{High case-to-capsule ratio, low radiation temperature beryllium capsule campaign}

One of the goals of the Los Alamos program is evaluate the benefits of beryllium capsules compared to other ablator options such as plastic (CH) or high density carbon (HDC). During the first beryllium ablator campaign, the target design for the campaign took advantage of the hohlraum development by the high foot campaign ${ }^{[1-3,11]}$ to minimize the number of shots needed to optimize the drive and provide the ability for some cross capsule comparisons. However, the target was not optimized for beryllium capsules. The experiments appear to show that beryllium capsules do not significantly change the hohlraum conditions compared to the $\mathrm{CH}$ ablator ${ }^{[12]}$. However, the implosions for both ablators were plagued by the same poor symmetry control making it difficult to compare based on nuclear performance. This is consistent with the work of Clark et al. ${ }^{[4]}$, which suggests one would not expect to see a difference in implosion performance between ablators with a high adiabat laser pulse due to the dominance of the low mode asymmetries. Thus, in order to both improve the implosion performance with respect to simulated expectations and provide an experimental platform to evaluate the potential benefits of beryllium capsules, a stable robust implosion platform is needed which will require a significant effort in both design studies and experiments. For the upcoming experiments, the case-tocapsule ratio is being increased while the convergence ratio

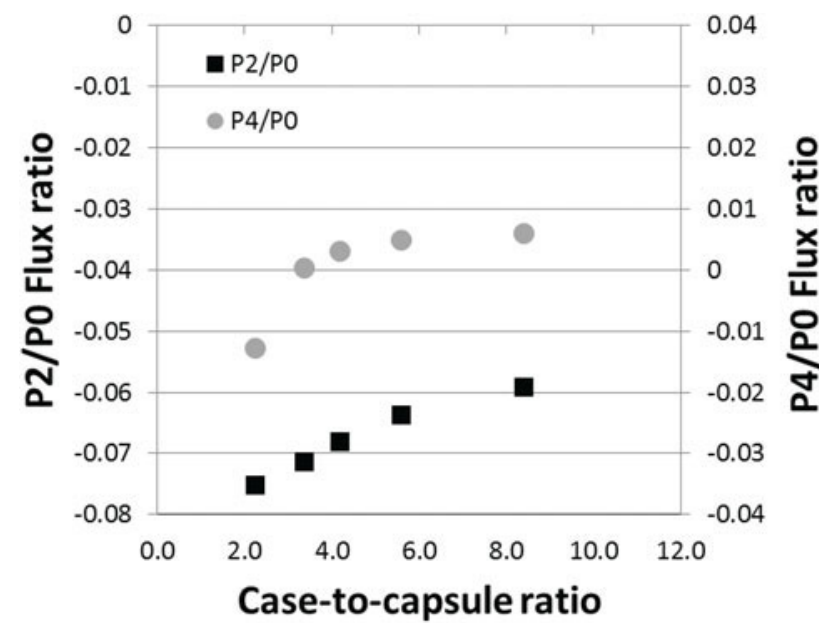

Figure 1. Plot of radiation flux symmetry versus case-to-capsule ratio for Legendre modes P2 and P4 normalized by the flux on the capsule.

is being decreased to improve implosion symmetry and reduce the effects of high mode perturbations.

While it is known that increasing the case-to-capsule ratio (ratio of hohlraum to capsule radius) smooths the $\mathrm{x}$-ray radiation pattern on the capsule, the benefits of radiation smoothing is not a strong function above a case-to-capsule ratio of $\sim 3^{[13]}$. Figure 1 shows a view factor calculation using VISRAD ${ }^{[14]}$ for the Legendre modes P2 and P4 normalized by the incident flux as a function of the case-tocapsule ratio. For these calculations, the laser beam pointing and hohlraum size is fixed and the capsule size varied to change the case-to-capsule ratio. The data show that the radiation smoothing of $\mathrm{P} 4$ does not change significantly above a case-to-capsule ratio of $\sim 3$ consistent with previous work $^{[13]}$. It also shows that it is difficult to reduce P2 which is not a sensitive function of the case-to-capsule ratio. So, why increase the case-to-capsule ratio at the expense of capsule drive? Radiation smoothing is not the only variable that affects the implosion symmetry. The propagation of the inner cone beams between the capsule and the hohlraum wall can be impeded by plasma blow-off, and the expansion of the gold wall where the outer cone beams deposit their energy also play an important role. Figure 2 shows plasma density maps from a $6720 \mu \mathrm{m}$ diameter gold hohlraum calculation using Hydra ${ }^{[15]}$ with beryllium capsules having both the diameters of 2200 and $1290 \mu \mathrm{m}$. The yellow regions are where the electron density is greater than the $1 / 4$ critical density for $351 \mathrm{~nm}$ light. The plots show the laser rays for the inner cone beams and it is clear for the $2200 \mu \mathrm{m}$ capsule that a portion of the beams terminate in the gold bubble and the capsule blows off. However, nearly the whole beam propagates to the wall in the case of the $1290 \mu \mathrm{m}$ diameter capsule. In this case, the gold wall expansion near the outer cone beams is smaller. Thus, the radiation symmetry and predictability of the hohlraum drive is expected to be in better agreement since the lasers should deposit their energy as designed. 

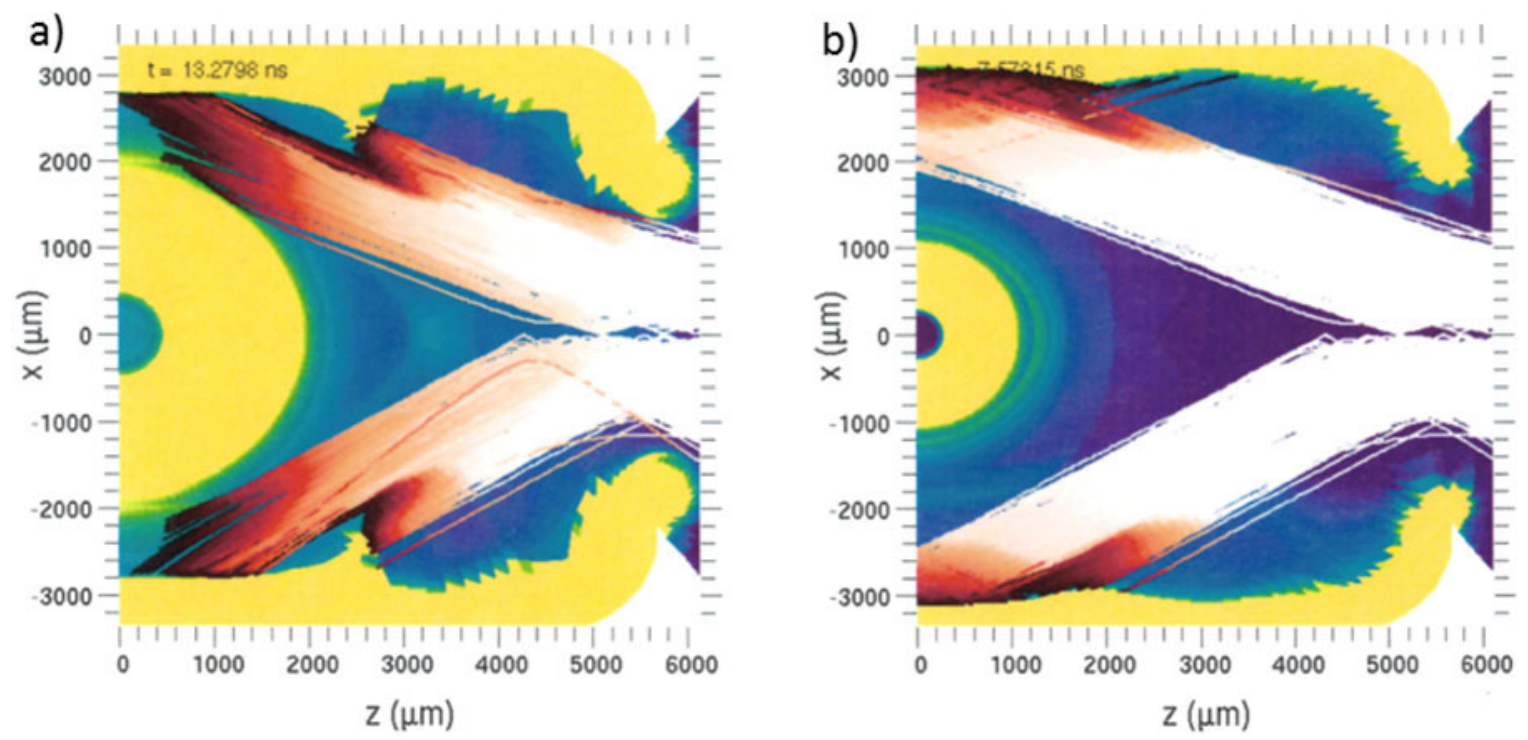

Figure 2. Plots of the hohlraum cross sections showing the laser ray traces with the hohlraum density for a (a) 2200 and (b) $1290 \mu \mathrm{m}$ outer diameter beryllium capsule. The yellow regions correspond to densities greater the $1 / 4$ critical for $351 \mathrm{~nm}$ light.

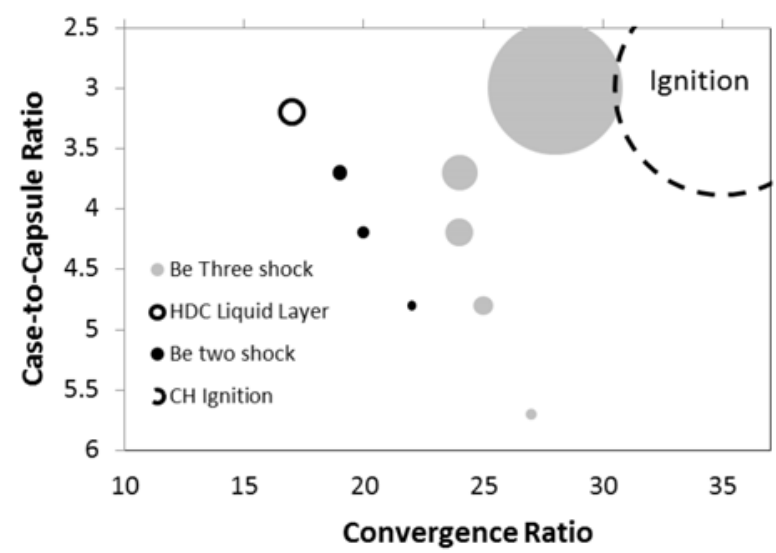

Figure 3. Case-to-capsule ratio versus convergence ratio design space for 1D simulations for beryllium with both two and three shock pulse shapes. Plot includes the design point for wetted foam targets and typical ignition targets. The size of the points is proportional to neutron yield.

With this in mind, a series of $1 \mathrm{D}$ clean simulations, i.e., no mix, have been completed to evaluate the energetics in caseto-capsule ratio versus convergence ratio space as shown in Figure 3. The solid black and gray points are for a two- and a three-shock pulse shape, respectively, and the size of the points are proportional to the neutron yield. The performance difference for the beryllium capsules at the same case-tocapsule ratio is a result of the different implosion adiabats for the different pulse shapes. The adiabat is used to enable some control over the convergence. The plot also shows the performance compared to ignition and the liquid layer design as a measure of the path towards ignition.

For the upcoming high case-to-capsule ratio campaign, an $1600 \mu \mathrm{m}$ outer diameter capsule in the $6.72 \mathrm{~mm}$ diameter hohlraum design has been chosen [Figure 4(a)]. The target design gives a case-to-capsule ratio of $\sim 4.2$ with a conver- gence of $\sim 25$. One consideration for choosing this design is the fact that two shock experiments using a $\mathrm{CH}$ capsule at this case-to-capsule ratio have shown good symmetry control with convergence ratios between $\sim 15$ and $19^{[16]}$. The initial radiation drive for the design is shown in Figure 4(b) which compares both the two-shock and three-shock drives. Of course, the picket energy in the three shock pulse can also be used to adjust the adiabat and thus increase or decrease the implosion convergence. For this design, one of the criteria is for the neutron yield to be greater than $2 \times 10^{14}$ to enable measurements with the nuclear diagnostics. The 1D yield for this design is $\sim 2 \times 10^{15}$, so even with a YOC of $\sim 10 \%$, we expect to meet this criterion.

Given the conservative target design, we expect to produce symmetric implosions with little time dependent swings. If we do achieve a 1D like implosion, the next step will be to move towards larger capsules to determine at which caseto-capsule ratio symmetry control for beryllium capsules degrades. From those experiments, we can hydro-scale the target and get an estimate of how much energy would be needed to achieve ignition with the low radiation temperature, high case-to-capsule beryllium capsule target design.

\section{Liquid layers}

Liquid fuel layers are an alternative approach to control the convergence ratio ${ }^{[17,18]}$. Unlike DT ice layers which must be fielded below the triple point for the DT fuel, liquid layers can be fielded over a range of temperatures from $\sim 21$ to $26 \mathrm{~K}$. As the temperature of the target is varied, the vapor pressure of the DT changes which in turn changes the density of the initial gas in the central cavity of the capsule. The different initial hot spot masses determine the convergence 
a)

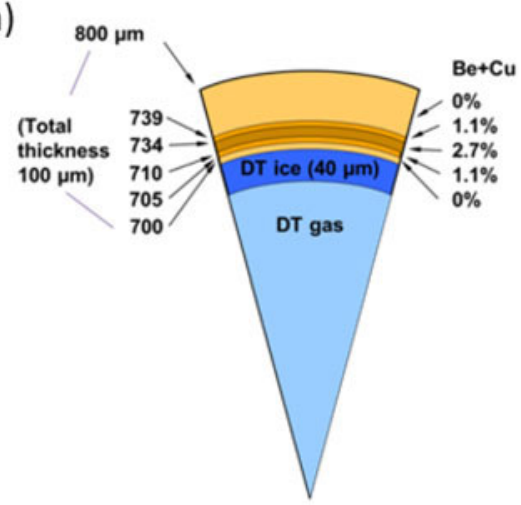

b)

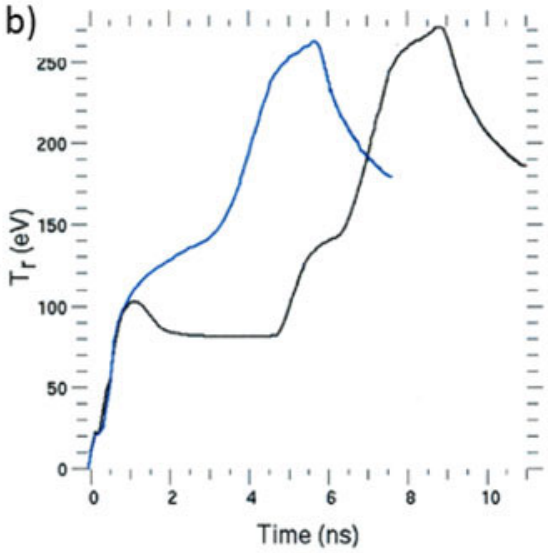

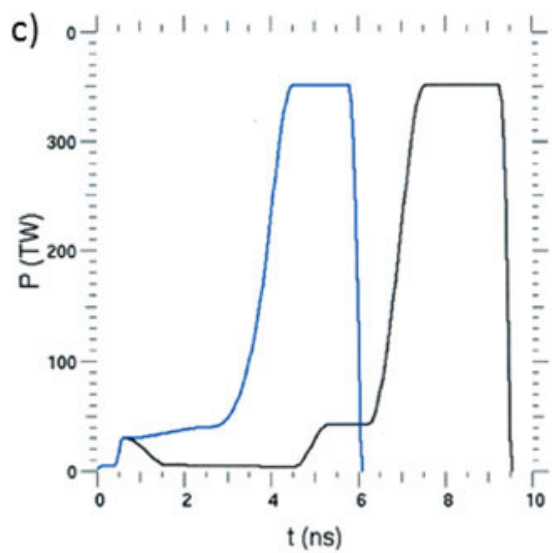

Figure 4. (a) Pie diagram for the $1600 \mu \mathrm{m}$ diameter capsule using a three shock pulse shape. (b) Radiation drive history for both the two and the three shock design using a $6.72 \mathrm{~mm}$ diameter hohlraum. (c) Laser power histories driving the two drives.

of the capsule implosion for a fixed drive due to partitioning of the energy between compressing the liquid fuel and heating the hot spot. Thus, as the initial hot spot mass is decreased, both the convergence and the liquid layer density are increased. This effectively changes both the convergence and the hot spot formation. The initial hot spot mass sets the amount of DT fuel from the liquid layer entering the hot spot during the implosion. For ice layers, a portion of the layer must be converted into the hot spot gas to initiate fusion, which may not be a stable process. Thus, these experiments are designed to investigate hot spot formation, in addition to providing a means to produce 1D like implosions.

Recent technological advances in target fabrication techniques for producing foam lined HDC capsules has made liquid layer implosions possible ${ }^{[19,20]}$. Unlike previous efforts in which $\mathrm{CH}$ was coated onto a foam sphere, generating the foam inside an HDC capsule produces a smooth interface between the foam and the ablator. In addition, the use of HDC capsules provides opportunities for a wider range of target designs such as vacuum hohlraums, and for potentially better ablation front stability control through reduced surface roughness ${ }^{[21,22]}$. While a sufficient number of capsules are currently being produced for experiments, there are still technical challenges for mass production of capsules with consistent foam characteristics such as thickness and uniformity. This needs to be addressed before transitioning from a research to a production project. Another technical issue being addressed is the size of the fill tube. Currently, a $30 \mu \mathrm{m}$ fill tube is needed to fill the capsules, apply the chemistry needed to produce the foam and dry the foam. The standard ignition capsules use a $10 \mu \mathrm{m}$ diameter fill tube. The larger fill tube is expected to degrade the implosion performance by initiating more mix from the ablator into the hot spot. It should also be noted that the current technology will allow liquid layers in beryllium capsules.

Recently, the first liquid layered target experiments were successfully fielded on NIF demonstrating the capability ${ }^{[23]}$. a)
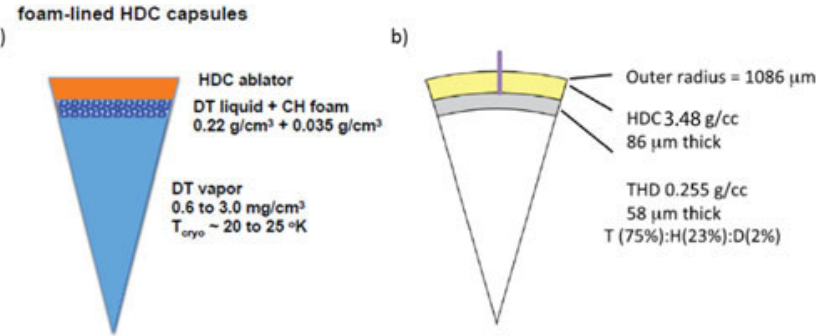

Figure 5. Pie diagrams for (a) liquid layer and (b) ice layered ${ }^{[22]}$ targets $^{2}$ using HDC capsules.

The target used a near vacuum hohlraum design with a $5750 \mu \mathrm{m}$ diameter hohlraum design used for the HDC campaign on $\mathrm{NIF}^{[21,22]}$. The capsule design is the same except for the liquid layer as shown in the pie diagrams in Figure 5. An in situ image through the laser entrance hole for the first liquid filled capsule shot on NIF before moving to target chamber center is shown in Figure 6(a). The image clearly shows the liquid $D_{2}$ layer inside the target. Figure 6(b) shows an unwrapped view along the equatorial direction through the side of the hohlraum. The image shows the variation in foam thickness for this particular capsule. For this experiment, the capsule was fielded at a temperature of $25.8 \mathrm{~K}$ corresponding to a vapor density in the center of the capsule of $3.8 \mathrm{mg} / \mathrm{cc}$. The preliminary convergence based on x-ray self-emission is $\sim 14$. These results are quite exciting and more analysis of the results of this shot are underway and will certainly be reported at a later date.

\section{Double shells}

Double shell targets provide a very different approach to ICF than single shells ${ }^{[24-30]}$. Double shell targets consist of a low $Z$ outer shell which separates the driver from the inner shell 
a)

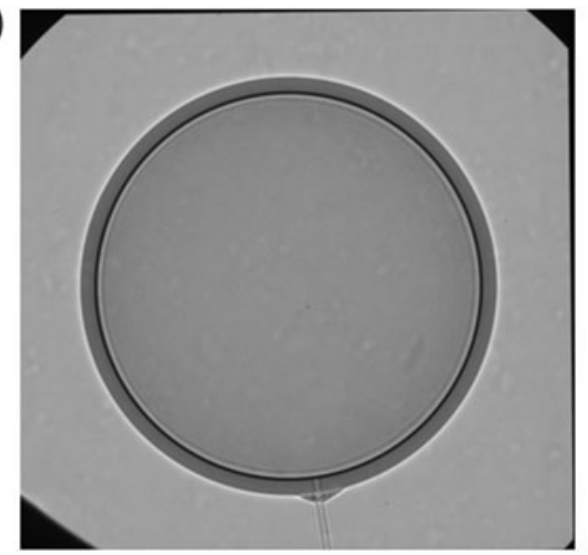

b)

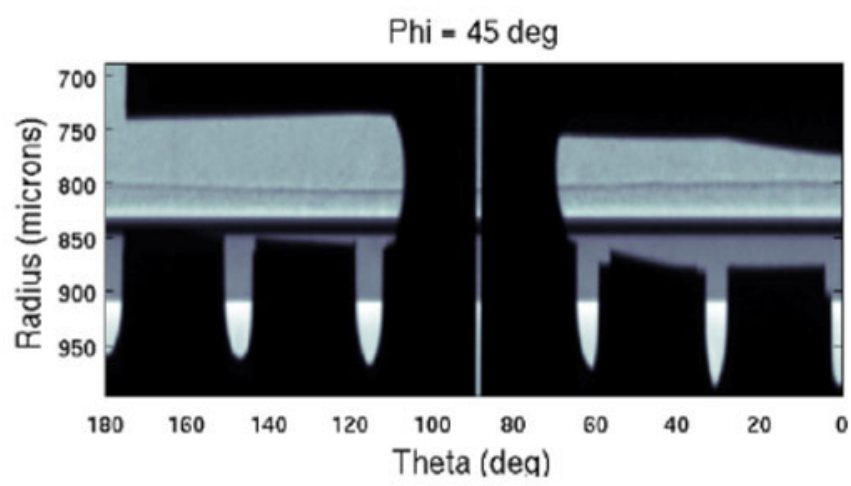

Figure 6. (a) X-ray image through the laser entrance hole of first liquid layered target fielded on NIF using liquid $D_{2}$. (b) Unwrapped image.

a)

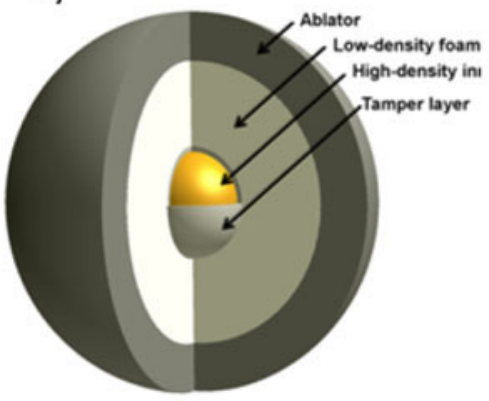

b)

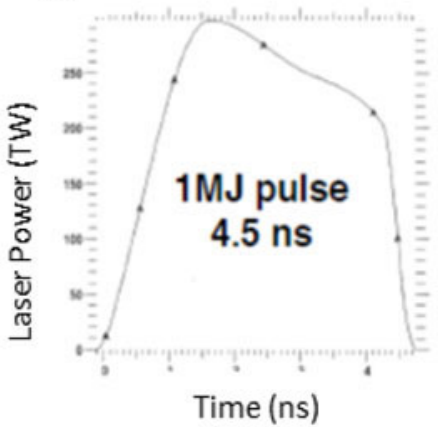

c) R-t plot

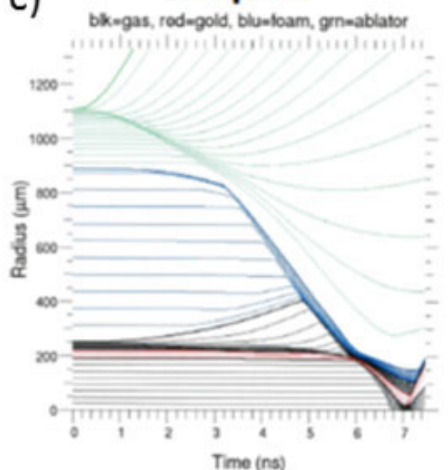

Figure 7. (a) Example of a double shell target. (b) Example laser pulse shape for an indirect double shell design. (c) Example of a double shell implosion in Lagrangian coordinates showing the collisions of the two shells and compression of the inner shell.

filled with the fusion fuel. A low density foam sits between the two shells as shown in Figure 7(a). The outer shell can be driven either directly with lasers impinging on the shell or indirectly by x-rays in a hohlraum. As the outer shell implodes, it collides with the inner shell transferring its momentum. The inner shell then compresses the fusion fuel through 'PdV' work to fusion conditions. Figures 7(b) and (c) show a sample laser pulse for an indirectly driven double shell target along with a plot showing the implosion process for a double shell target in Lagrangian coordinates. The plot of the implosion shows the outer shell accelerating and colliding with the inner shell compressing the fusion fuel.

Unlike single shells that use a central hot spot to ignite and initiate burn of the cold dense fuel surrounding the hot spot, double shells ignite via volume ignition, i.e., heating the entire fuel volume to fusion conditions. Volume ignition with similar laser energies as for hot spot ignition is possible because of several design factors. The inner shell is made of a mid- to high- $Z$ material which prevents radiation energy from escaping the fuel known as radiation trapping. The process of transferring momentum between the outer and inner shell tends to hold the fuel together longer increasing the inertial confinement time. This process is known as tamping. Double shell targets also hold a smaller fuel mass to reduce the energy density required for ignition, which does lead to lower yields for the same laser energy. The primary question is whether or not double shell target designs are more stable/robust than single shell ICF target designs. LANL is currently evaluating such target designs for $\mathrm{NIF}^{[31]}$.

Double shell targets have a different set of concerns than single shell targets. For double shells, the ablative physics of the outer shell, the inflight aspect ratio, pulse shaping and the fact that a fuel layer is not needed are advantages. In addition, the implosions do not require high implosion velocities. The primary trade-off is the engineering challenge of building the precision double shell targets. For double shells the other key challenges compared to single shell hot spot ignition is mix at the inner shell fuel interface and preheating of the inner shell by high energy x-rays. Mixing of high $z$ material into the fuel leads to more cooling of the hot spot through conduction. Preheating of the inner shell by high energy hohlraum photons causes the inner shell to expand which can enhance mix and reduce momentum transfer between the two shells. In Figure 7(c), it 
is interesting to note the inner shell is expanding before the collision showing the effect of preheat. Another outstanding question is whether or not double shell capsules will be less susceptible to drive asymmetry since the inner shell convergence is much less than for single shell capsules and the foam between the two shells mitigates symmetry feedthrough or if the overall high convergence of the system affects performance. The work over the next few years will be directed towards identifying and attacking the key problems associated with double shell to determine the size of these challenges.

\section{Conclusions}

As we continue to march towards ICF ignition, many challenges remain. Experiments have identified several issues which are in the midst of being addressed. To assist our understanding in order to mitigate these problems, to identify other potential problems, and to evaluate modeling deficiencies, it is prudent to develop target implosions that behave as near as possible to 1D simulations, i.e., ideal as possible. This means developing less stressful target designs by increasing the case-to-capsule ratio and reducing the implosion convergence. LANL has adopted three approaches in line with this strategy, a low radiation temperature beryllium target design, liquid fuel layer targets, and double shell targets. These platforms are being developed to support ignition science experiments needed to provide guidance on the most likely path towards ignition.

\section{Acknowledgements}

The authors wish to thank the General Atomics and LLNL target fabrication for their development of the beryllium capsules currently being used. They also wish to thank the NIF cryogenics team and target fabrication for development of the liquid layer capsules and efforts to field the first target experiment. This work was performed under the auspices of the US Department of Energy by LANL under Contract DEAC52-06NA25396 and by LLNL under Contract DE-AC5 2-07NA27344.

\section{References}

1. T. R. Dittrich, O. A. Hurricane, D. A. Callahan, E. L. Dewald, T. Doeppner, D. E. Hinkel, L. F. Berzak Hopkins, S. Le Pape, T. Ma, J. L. Milovich, J. C. Moreno, P. K. Patel, H. S. Park, B. A. Remington, J. D. Salmonson, and J. L. Kline, Phys. Rev. Lett. 112, 055002 (2014).

2. O. A. Hurricane, D. A. Callahan, D. T. Casey, E. L. Dewald, T. R. Dittrich, T. Doeppner, M. A. Barrios Garcia, D. E. Hinkel, L. F. Berzak Hopkins, P. Kervin, J. L. Kline, S. Le Pape, T. Ma, A. G. MacPhee, J. L. Milovich, J. Moody, A. E. Pak, P. K. Patel, H. S. Park, B. A. Remington, H. F. Robey, J. D.
Salmonson, P. T. Springer, R. Tommasini, L. R. Benedetti, J. A. Caggiano, P. Celliers, C. Cerjan, R. Dylla-Spears, D. Edgell, M. J. Edwards, D. Fittinghoff, G. P. Grim, N. Guler, N. Izumi, J. A. Frenje, M. Gatu Johnson, S. Haan, R. Hatarik, H. Herrmann, S. Khan, J. Knauer, B. J. Kozioziemski, A. L. Kritcher, G. Kyrala, S. A. Maclaren, F. E. Merrill, P. Michel, J. Ralph, J. S. Ross, J. R. Rygg, M. B. Schneider, B. K. Spears, K. Widmann, and C. B. Yeamans, Phys. Plasmas 21, 056314 (2014).

3. H. S. Park, O. A. Hurricane, D. A. Callahan, D. T. Casey, E. L. Dewald, T. R. Dittrich, T. Doeppner, D. E. Hinkel, L. F. Berzak Hopkins, S. Le Pape, T. Ma, P. K. Patel, B. A. Remington, H. F. Robey, J. D. Salmonson, and J. L. Kline, Phys. Rev. Lett. 112, 055001 (2014).

4. D. S. Clark, C. R. Weber, J. L. Milovich, J. D. Salmonson, A. L. Kritcher, S. W. Haan, B. A. Hammel, D. E. Hinkel, O. A. Hurricane, O. S. Jones, M. M. Marinak, P. K. Patel, H. F. Robey, S. M. Sepke, and M. J. Edwards, Phys. Plasmas 23, 056302 (2016).

5. S. R. Nagel, S. W. Haan, J. R. Rygg, M. Barrios, L. R. Benedetti, D. K. Bradley, J. E. Field, B. A. Hammel, N. Izumi, O. S. Jones, S. F. Khan, T. Ma, A. E. Pak, R. Tommasini, and R. P. J. Town, Phys. Plasmas 22, 022704 (2015).

6. R. Tommasini, J. E. Field, B. A. Hammel, O. L. Landen, S. W. Haan, C. Aracne-Ruddle, L. R. Benedetti, D. K. Bradley, D. A. Callahan, E. L. Dewald, T. Doeppner, M. J. Edwards, O. A. Hurricane, N. Izumi, O. A. Jones, T. Ma, N. B. Meezan, S. R. Nagel, J. R. Rygg, K. S. Segraves, M. Stadermann, R. J. Strauser, and R. P. J. Town, Phys. Plasmas 22, 056315 (2015).

7. A. N. Simakov, D. C. Wilson, S. A. Yi, J. L. Kline, D. S. Clark, J. L. Milovich, J. D. Salmonson, and S. H. Batha, Phys. Plasmas 21, 022701 (2014).

8. D. C. Wilson, P. A. Bradley, N. M. Hoffman, F. J. Swenson, D. P. Smitherman, R. E. Chrien, R. W. Margevicius, D. J. Thoma, L. R. Foreman, J. K. Hoffer, S. R. Goldman, S. E. Caldwell, T. R. Dittrich, S. W. Haan, M. M. Marinak, S. M. Pollaine, and J. J. Sanchez, Phys. Plasmas 5, 1953 (1998).

9. S. A. Yi, A. N. Simakov, D. C. Wilson, R. E. Olson, J. L. Kline, D. S. Clark, B. A. Hammel, J. L. Milovich, J. D. Salmonson, B. J. Kozioziemski, and S. H. Batha, Phys. Plasmas 21, 092701 (2014).

10. T. R. Dittrich, S. W. Haan, S. Pollaine, A. K. Burnham, and G. L. Strobel, Fusion Technol. 31, 402 (1997).

11. D. A. Callahan, N. B. Meezan, S. H. Glenzer, A. J. MacKinnon, L. R. Benedetti, D. K. Bradley, J. R. Celeste, P. M. Celliers, S. N. Dixit, T. Doppner, E. G. Dzentitis, S. Glenn, S. W. Haan, C. A. Haynam, D. G. Hicks, D. E. Hinkel, O. S. Jones, O. L. Landen, R. A. London, A. G. MacPhee, P. A. Michel, J. D. Moody, J. E. Ralph, H. F. Robey, M. D. Rosen, M. B. Schneider, D. J. Strozzi, L. J. Suter, R. P. J. Town, K. Widmann, E. A. Williams, M. J. Edwards, B. J. MacGowan, J. D. Lindl, L. J. Atherton, G. A. Kyrala, J. L. Kline, R. E. Olson, D. Edgell, S. P. Regan, A. Nikroo, H. Wilkins, J. D. Kilkenny, and A. S. Moore, Phys. Plasmas 19, 056305 (2012).

12. J. L. Kline, S. A. Yi, A. N. Simakov, R. E. Olson, D. C. Wilson, G. A. Kyrala, T. S. Perry, S. H. Batha, A. B. Zylstra, E. L. Dewald, R. Tommasini, J. E. Ralph, D. J. Strozzi, A. G. MacPhee, D. A. Callahan, D. E. Hinkel, O. A. Hurricane, J. L. Milovich, J. R. Rygg, S. F. Khan, S. W. Haan, P. M. Celliers, D. S. Clark, B. A. Hammel, B. Kozioziemski, M. B. Schneider, M. M. Marinak, H. G. Rinderknecht, H. F. Robey, J. D. Salmonson, P. K. Patel, T. Ma, M. J. Edwards, M. Stadermann, S. Baxamusa, C. Alford, M. Wang, A. Nikroo, 
N. Rice, D. Hoover, K. P. Youngblood, H. Xu, H. Huang, and H. Sio, Phys. Plasmas 23, 056310 (2016).

13. John Lindl, Phys. Plasmas 2, 3933 (1995).

14. J. J. MacFarlane, J. Quant. Spectrosc. Radiat. Transfer 81, 287 (2003).

15. M. M. Marinak, G. D. Kerbel, N. A. Gentile, O. Jones, D. Munro, S. Pollaine, T. R. Dittrich, and S. W. Haan, Phys. Plasmas 8, 2275 (2001).

16. S. F. Khan, S. A. MacLaren, J. D. Salmonson, T. Ma, G. A. Kyrala, J. E. Pino, J. R. Rygg, J. E. Field, R. Tommasini, J. E. Ralph, D. P. Turnbull, A. J. Mackinnon, K. L. Baker, L. R. Benedetti, D. K. Bradley, P. M. Celliers, E. L. Dewald, T. R. Dittrich, L. B. Hopkins, N. Izumi, M. L. Kervin, J. L. Kline, S. R. Nagel, A. Pak, and R. E. Tipton, Phys. Plasmas 23, 042708 (2016).

17. R. E. Olson, R. J. Leeper, S. A. Yi, J. L. Kline, A. B. Zylstra, R. R. Peterson, R. Shah, T. Braun, J. Biener, B. J. Kozioziemski, J. D. Sater, M. M. Biener, A. V. Hamza, A. Nikroo, L. Berzak Hopkins, D. Ho, S. LePape, and N. B. Meezan, J. Phys.: Conf. Ser. 717, 012042 (2016).

18. R. E. Olson and R. J. Leeper, Phys. Plasmas 20, 092705 (2013).

19. J. Biener, C. Dawedeit, S. H. Kim, T. Braun, M. A. Worsley, A. A. Chernov, C. C. Walton, T. M. Willey, S. O. Kucheyev, S. J. Shin, Y. M. Wang, M. M. Biener, J. R. I. Lee, B. J. Kozioziemski, T. van Buuren, K. J. J. Wu, Jr., J. H. Satcher, and A. V. Hamza, Nucl. Fusion 52, 062001 (2012).

20. T. Braun, C. C. Walton, C. Dawedeit, M. M. Biener, S. H. Kim, T. M. Willey, X. Xiao, A. van Buuren, A. V. Hamza, and J. Biener, ACS Appl. Mater. Interfaces 8, 2600 (2016).

21. L. F. Berzak Hopkins, N. B. Meezan, S. Le Pape, L. Divol, A. J. Mackinnon, D. D. Ho, M. Hohenberger, O. S. Jones, G. Kyrala, J. L. Milovich, A. Pak, J. E. Ralph, J. S. Ross, L. R. Benedetti, J. Biener, R. Bionta, E. Bond, D. Bradley, J. Caggiano, D. Callahan, C. Cerjan, J. Church, D. Clark, T. Döppner, R. Dylla-Spears, M. Eckart, D. Edgell, J. Field, D. N. Fittinghoff, M. Gatu Johnson, G. Grim, N. Guler, S. Haan, A. Hamza, E. P. Hartouni, R. Hatarik, H. W. Herrmann, D. Hinkel, D. Hoover, H. Huang, N. Izumi, S. Khan, B. Kozioziemski, J. Kroll, T. Ma, A. MacPhee, J. McNaney, F. Merrill, J. Moody, A. Nikroo, P. Patel, H. F. Robey, J. R. Rygg, J. Sater, D. Sayre, M. Schneider, S. Sepke, M. Stadermann, W. Stoeffl, C. Thomas, R. P. J. Town, P. L. Volegov, C. Wild, C. Wilde, E. Woerner, C. Yeamans, B. Yoxall, J. Kilkenny, O. L. Landen, W. Hsing, and M. J. Edwards, Phys. Rev. Lett. 114, 175001 (2015).

22. A. J. Mackinnon, J. L. Kline, S. N. Dixit, S. H. Glenzer, M. J. Edwards, D. A. Callahan, N. B. Meezan, S. W. Haan, J. D. Kilkenny, T. Doppner, D. R. Farley, J. D. Moody, J. E. Ralph, B. J. MacGowan, O. L. Landen, H. F. Robey, T. R. Boehly, P. M. Celliers, J. H. Eggert, K. Krauter, G. Frieders, G. F. Ross, D. G. Hicks, R. E. Olson, S. V. Weber, B. K. Spears, J. D. Salmonsen, P. Michel, L. Divol, B. Hammel, C. A. Thomas, D. S. Clark, O. S. Jones, P. T. Springer, C. J. Cerjan, G. W. Collins, V. Y. Glebov, J. P. Knauer, C. Sangster, C. Stoeckl, P. McKenty, J. M. McNaney, R. J. Leeper, C. L. Ruiz, G. W. Cooper, A. G. Nelson, G. G. A. Chandler, K. D. Hahn, M. J. Moran, M. B. Schneider, N. E. Palmer, R. M. Bionta, E. P. Hartouni, S. LePape, P. K. Patel, N. Izumi, R. Tommasini, E. J. Bond, J. A. Caggiano, R. Hatarik, G. P. Grim, F. E. Merrill, D. N. Fittinghoff, N. Guler, O. Drury,
D. C. Wilson, H. W. Herrmann, W. Stoeffl, D. T. Casey, M. G. Johnson, J. A. Frenje, R. D. Petrasso, A. Zylestra, H. Rinderknecht, D. H. Kalantar, J. M. Dzenitis, P. Di Nicola, D. C. Eder, W. H. Courdin, G. Gururangan, S. C. Burkhart, S. Friedrich, D. L. Blueuel, L. A. Bernstein, M. J. Eckart, D. H. Munro, S. P. Hatchett, A. G. Macphee, D. H. Edgell, D. K. Bradley, P. M. Bell, S. M. Glenn, N. Simanovskaia, M. A. Barrios, R. Benedetti, G. A. Kyrala, R. P. J. Town, E. L. Dewald, J. L. Milovich, K. Widmann, A. S. Moore, G. LaCaille, S. P. Regan, L. J. Suter, B. Felker, R. C. Ashabranner, M. C. Jackson, R. Prasad, M. J. Richardson, T. R. Kohut, P. S. Datte, G. W. Krauter, J. J. Klingman, R. F. Burr, T. A. Land, M. R. Hermann, D. A. Latray, R. L. Saunders, S. Weaver, S. J. Cohen, L. Berzins, S. G. Brass, E. S. Palma, R. R. Lowe-Webb, G. N. McHalle, P. A. Arnold, L. J. Lagin, C. D. Marshall, G. K. Brunton, D. G. Mathisen, R. D. Wood, J. R. Cox, R. B. Ehrlich, K. M. Knittel, M. W. Bowers, R. A. Zacharias, B. K. Young, J. P. Holder, J. R. Kimbrough, T. Ma, K. N. La Fortune, C. C. Widmayer, M. J. Shaw, G. V. Erbert, K. S. Jancaitis, J. M. DiNicola, C. Orth, G. Heestand, R. Kirkwood, C. Haynam, P. J. Wegner, P. K. Whitman, A. Hamza, E. G. Dzenitis, R. J. Wallace, S. D. Bhandarkar, T. G. Parham, R. Dylla-Spears, E. R. Mapoles, B. J. Kozioziemski, J. D. Sater, C. F. Walters, B. J. Haid, J. Fair, A. Nikroo, E. Giraldez, K. Moreno, B. Vanwonterghem, R. L. Kauffman, S. Batha, D. W. Larson, R. J. Fortner, D. H. Schneider, J. D. Lindl, R. W. Patterson, L. J. Atherton, and E. I. Moses, Phys. Rev. Lett. 108, 215005 (2012).

23. R. E. Olson, R. J. Leeper, J. L. Kline, A. B. Zylstra, S. A. Yi, J. Biener, T. Braun, B. J. Kozioziemski, J. D. Sater, P. A. Bradley, R. R. Peterson, B. M. Haines, L. Yin, L. F. Berzak Hopkins, N. B. Meezan, C. Walters, M. M. Biener, C. Kong, J. W. Crippen, G. A. Kyrala, R. C. Shah, H. W. Herrmann, D. C. Wilson, A. V. Hamza, A. Nikroo, and S. H. Batha, Phys. Rev. Lett. (2016) (accepted for publication).

24. P. Amendt, C. Cerjan, A. Hamza, D. E. Hinkel, J. L. Milovich, and H. F. Robey, Phys. Plasmas 14, 056312 (2007).

25. P. A. Amendt, H. F. Robey, H. S. Park, R. E. Tipton, R. E. Turner, J. L. Milovich, M. Bono, R. Hibbard, H. Louis, R. Wallace, and V. Y. Glebov, Phys. Rev. Lett. 94, 065004 (2005).

26. J. L. Milovich, P. Amendt, M. Marinak, and H. Robey, Phys. Plasmas 11, 1552 (2004).

27. H. F. Robey, T. S. Perry, H. S. Park, P. Amendt, C. M. Sorce, S. M. Compton, K. M. Campbell, and J. P. Knauer, Phys. Plasmas 12, 072701 (2005).

28. W. S. Varnum, N. D. Delamater, S. C. Evans, P. L. Gobby, J. E. Moore, J. M. Wallace, R. G. Watt, J. D. Colvin, R. Turner, V. Glebov, J. Soures, and C. Stoeckl, Phys. Rev. Lett. 84, 5153 (2000).

29. G. A. Kyrala, N. Delamater, D. Wilson, J. Guzik, D. Haynes, M. Gunderson, K. Klare, R. W. Watt, W. M. Wood, and W. Varnum, Laser Part. Beams 23, 187 (2005).

30. G. A. Kyrala, M. A. Gunderson, N. D. Delamater, D. A. Haynes, D. C. Wilson, J. A. Guzik, and K. A. Klare, Phys. Plasmas 13, 056306 (2006).

31. D. S. Montgomery, W. S. Daughton, M. A. Gunderson, A. N. Simakov, D. C. Wilson, R. G. Watt, J. L. Kline, A. C. Hayes, H. W. Herrmann, M. Boswell, C. R. Danly, F. E. Merrill, S. H. Batha, P. A. Amendt, J. L. Milovich, and H. F. Robey, Plans for Double Shell Experiments on NIF, http://meetings.aps.org /link/BAPS.2015.DPP.BO4.12 (2015). 